\title{
Original
}

\section{Salivary nitrate-nitrite conversion capacity after nitrate ingestion and incidence of Veillonella spp. in elderly individuals}

\author{
Takahiro Mitsui1), Masahiko Saito2), and Ryô Harasawa3) \\ 1)Department of Home Economics, Faculty of Education, Iwate University, Morioka, Japan \\ 2)Iwate Prefectural Central Hospital, Morioka, Japan \\ 3)The Iwate Research Center for Wildlife Diseases, Morioka, Japan
}

(Received September 19, 2017; Accepted November 9, 2017)

\begin{abstract}
Dietary nitrate has several beneficial effects, including blood pressure reduction and improved oxygen consumption efficiency, but in order to do so it must first be reduced to nitrite by oral bacteria. Veillonella spp., a strictly anaerobic group, are the most prevalent nitrate-reducing bacteria in the oral cavity. In response to some early studies that have hinted at inter- and intra-individual variation in salivary nitrate-nitrite conversion capacity, the purpose of the present study was to investigate the incidence of and variation in the Veillonella species $V$. atypica, $V$. dispar, and $V$. rogosae by direct PCR and to assess salivary nitrate-nitrite conversion capacity and its reproducibility after dietary nitrate consumption in 24 elderly individuals. $V$. atypica, $V$. dispar, and $V$. rogosae were detected in $10(41.7 \%), 24(100 \%)$, and $14(58.3 \%)$ participants, respectively. The coefficients of correlation between the first and second experiments on increased nitrate/nitrite were 0.637 and 0.583 , respectively, both of which were statistically significant $(P<0.01)$. In both experiments, 6 participants produced relatively low levels of nitrite $(<0.5$ $\mathrm{mM} \Delta$ nitrite) while 7 produced relatively high levels ( $>1.0 \mathrm{mM} \Delta$ nitrite). The data suggested that $V$. dispar was the most prevalent species, being present even in individuals producing low levels of salivary nitrite.
\end{abstract}

Correspondence to Dr. Takahiro Mitsui, Department of Home Economics, Faculty of Education, Iwate University, 3-18-33 Ueda, Morioka, Iwate 020-8550, Japan

Fax:+81-19-621-6600 Email: mitsui@iwate-u.ac.jp

J-STAGE Advance Publication: August 12, 2018

doi.org/10.2334/josnusd.17-0337

DN/JST.JSTAGE/josnusd/17-0337
Keywords: salivary nitrate; salivary nitrite; Veillonella; inter- and intra-individual variation.

\section{Introduction}

In humans, dietary nitrate is obtained primarily from vegetables such as lettuce and spinach (1). Historically, ingestion of nitrate has been considered deleterious because it is rapidly reduced by oral microbial activity to toxic nitrite, which is a possible cause of infant methemoglobinemia and is linked to the formation of carcinogenic $N$-nitrosamine (1). Over the past two decades, however, it has also become clear that nitrate/nitrite also has beneficial effects such as reduction of blood pressure (2-4) and oxygen consumption (5), and antibacterial activity in the oral cavity (6-8) and upper intestinal tract (9). Nitric oxide produced through the reduction of dietary nitrate to nitrite by oral bacteria may have a vasodilatory effect, as does endogenous nitric oxide (NO) derived from L-arginine (10).

Ingested nitrate is absorbed rapidly into the bloodstream from the upper intestine. Approximately $75 \%$ of circulating nitrate is excreted by the kidneys, while the rest is concentrated in the salivary glands by the active transport system, increasing its concentration there to as much as 10 times the concentration found in plasma (11). Salivary levels of nitrate/nitrite can increase markedly after nitrate loading, those of nitrate rising from approximately $0.7 \mathrm{mM}$ to $>15 \mathrm{mM}$ and those of nitrite from 0.3 $\mathrm{mM}$ to $>2.0 \mathrm{mM}$ (12). Previous studies examining the effect of dietary nitrate have also revealed great variation in salivary nitrate/nitrite conversion after nitrate loading, which is the result of inter-individual differences in nitrate 
metabolism. Some early studies published in the 1980s, for example, suggested a distinction between individuals with greater and lesser capacities for nitrate-nitrite conversion $(13,14)$. Despite its physiological importance, however, the inter- and intra-individual variation in salivary nitrate/nitrite conversion after nitrate loading has received little attention to date.

Many oral facultative and strictly anaerobic bacteria possess nitrate and nitrite reductases (15-17). Veillonella spp., a strictly anaerobic group, are the most prevalent nitrate-reducing bacteria in the oral cavity, where they are considered to make a major contribution to nitrate reduction (16). So far, six Veillonella species have been isolated from humans; among these, V. atypica, V. dispar, and $V$. rogosae are predominant in the oral cavity (18).

Variations in microflora and the nitrate-nitrite-NO pathway seem to be matters of greater concern for middleaged and older individuals because the management of cardiovascular disorders such as high blood pressure is more important for these age groups. The purpose of the present study was to assess the increase in salivary nitrate/nitrite that occurs after nitrate loading and its inter- and intra-individual variations, the distribution of the three dominant Veillonella spp., and the presence of any relationship between these factors in humans over 60 years of age.

\section{Materials and Methods \\ Participants}

For this study, 24 (12 male and 12 female) ambulatory non-smoking local residents with a mean age of $70.3 \pm$ 6.0 (SD) years were enrolled. Participants were invited to enroll at a municipal job center or a local community organization. None of the participants had used antibiotics or mouthwash in the last three months. Their prescription notebooks were handed in at the first visit. Written informed consent was obtained from all participants, and the study protocol was approved by the Human Ethics Committee of Iwate University (No. 201407).

\section{Study protocol}

All participants were asked to refrain from eating vegetables at dinner on the eve of each sampling day and to skip breakfast. They arrived at the laboratory prior to 7:30 a.m. for each experiment and rested for $10 \mathrm{~min}$ before the experiment began. Just before the nitrate load was consumed, blood pressure was measured using an EW-BW13 (Panasonic, Osaka, Japan) with the participant in a sitting position. Hypertension was defined as a systolic blood pressure of $\geq 140 \mathrm{mmHg}$ and/or a diastolic blood pressure $\geq 90 \mathrm{mmHg}$ (Ministry of Health, Labour, and Welfare) or current medication for hypertension. A $1.0-\mathrm{mL}$ whole saliva and bacteria sample was also collected. The dorsal surface of the tongue in each participant was swabbed five times using a sterile cottonwool stick to collect bacteria; the surface of the tongue is the major area where nitrate reduction occurs in the oral cavity (16). The stick was immediately placed in 1 $\mathrm{mL}$ of phosphate-buffered saline (PBS) solution to create a bacterial suspension. Following baseline collection, participants consumed $100 \mathrm{~mL}$ of beetroot juice (James White Drinks Ltd., Ashbocking, UK), which is equivalent to $372 \mathrm{mg}$ of nitrate. Afterwards, blood pressure was measured at 15-min intervals and saliva samples were collected at 30-min intervals for $90 \mathrm{~min}$. Bacterial and saliva samples were stored at $-20^{\circ} \mathrm{C}$ immediately after collection. The procedure was repeated twice with a oneweek interval.

\section{Analysis of salivary nitrate and nitrite}

Our method of salivary nitrite measurement has been described previously (7). Each whole saliva sample was diluted 200-400-fold using distilled water and filtered using an ADVANTEC Grade No. 2 filter for nitrate/nitrite analysis. A standard colorimetric method involving diazotization with sulphanilamide coupled with $N$-(1-naphthyl)ethylendiamine to form an azo-dye was used, and the samples were tested spectroscopically at $540 \mathrm{~nm}$. Nitrate was measured after reduction to nitrite by passing it though a cadmium-copper column.

\section{Direct polymerase chain reaction (PCR) protocol}

The following species-specific forward primers in the $r р о B$ gene were used for identification of the three bacterial species: ATYF (5'-TCTCTTTGGGAAGAA TTAGAACGC-3') for $V$. atypica, DISF (5'-AACGCGTTGAAATTCGTCATGAAC-3') for $V$. dispar, and ROGF (5'-ATTGCAGAAGATGTAACATGAAGC-3') for $V$. rogosae. In addition, the reverse primer VR (5'GTGTAACAAGGGAGTACGGACC-3') was used for all species (19). The expected molecular weights of the PCR products were $384 \mathrm{bp}$ for $V$. atypica, $321 \mathrm{bp}$ for $V$. dispar, and $604 \mathrm{bp}$ for $V$. rogosae (20). The primers were synthesized by BEX Co. Ltd. (Tokyo, Japan).

The PCR mixture $(50 \mu \mathrm{L})$ was composed of $24 \mu \mathrm{L}$ $\mathrm{H}_{2} \mathrm{O}, 12 \mu \mathrm{L}$ bacterial slurry serially diluted 10 -fold with PBS $\left(10^{-1}\right.$ and $\left.10^{-2}\right), 12 \mu \mathrm{L}$ direct PCR kit (KAPA2G Robust HotStart ReadyMix with dye, Kapa Biosystems, Cape Town, South Africa), and $1 \mu \mathrm{L}$ of each primer (50 $\mathrm{pmol} / \mu \mathrm{L}$ ). This PCR polymerase offers high amplification efficiency even in the presence of an inhibitor and is a useful tool for forensic samples (20). 
Table 1 Baseline characteristics and increases in nitrate/nitrite concentrations in saliva after nitrate loading

\begin{tabular}{ll}
\hline$n$ & $24(12$ male, 12 female $)$ \\
age, years & $70.3 \pm 6.0$ \\
normotensive & 10 \\
grey-area & 2 \\
hypertensive & 12 \\
first, baseline nitrate, $\mathrm{mM}$ & $0.25(0.02-1.60)$ \\
first, baseline nitrite, $\mathrm{mM}$ & $0.26(0.06-0.88)$ \\
second, baseline nitrate, $\mathrm{mM}$ & $0.29(0.08-0.72)$ \\
second, baseline nitrite, $\mathrm{mM}$ & $0.20(0.05-0.74)$ \\
first, $\Delta$ salivary nitrate, $\mathrm{mM}$ & $1.26(0.03-3.67)$ \\
first, $\Delta$ salivary nitrite, $\mathrm{mM}$ & $0.83(0.04-4.23)$ \\
second, $\Delta$ salivary nitrate, $\mathrm{mM}$ & $0.93(0.05-2.09)$ \\
second, $\Delta$ salivary nitrite, $\mathrm{mM}$ & $0.72(0.03-3.35)$ \\
\hline Data are expressed as mean $\pm \mathrm{SD}$ or median (range).
\end{tabular}
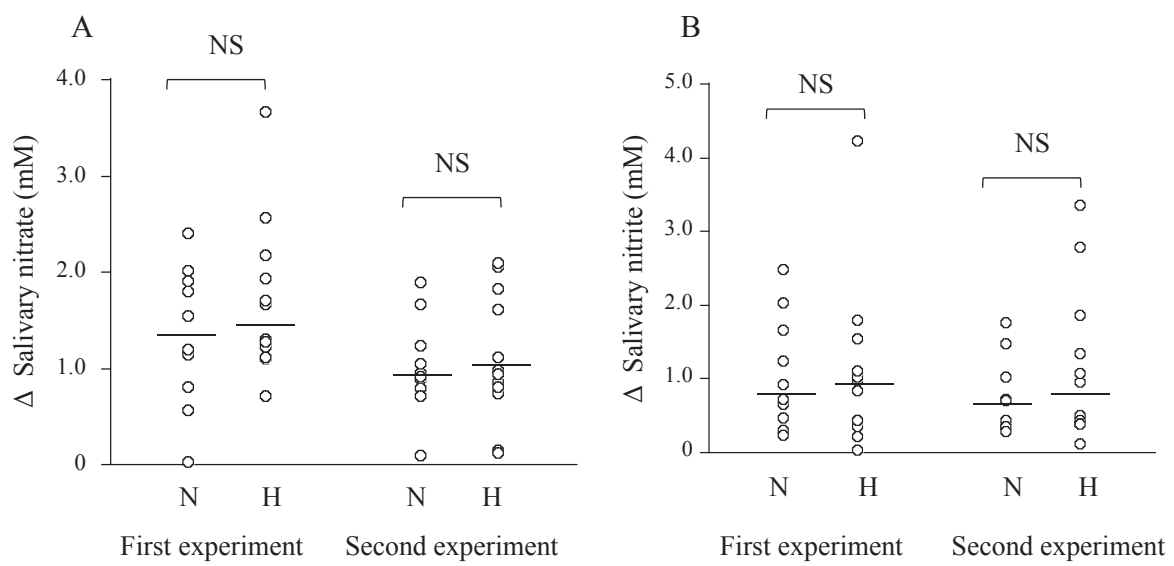

Fig. 1 Increases in salivary (A), nitrate, and (B) nitrite after nitrate loading in normotensive $(n=10)$ and hypertensive participants $(n=12)$. Horizontal bars represent median. N; normotensive, $\mathrm{H}$; hypertensive, NS; not significant.

PCR was performed in a thermal cycler (Model TP600, Takara Bio Inc., Otsu, Japan). The reaction mixture was predenatured at $95^{\circ} \mathrm{C}$ for $3 \mathrm{~min}$, followed by 30 cycles of denaturing at $95^{\circ} \mathrm{C}$ for $15 \mathrm{~s}$, annealing at $60^{\circ} \mathrm{C}$ for $15 \mathrm{~s}$, and extension at $72^{\circ} \mathrm{C}$, with a final extension at $72^{\circ} \mathrm{C}$ for $10 \mathrm{~min}$. The $12 \mu \mathrm{L}$ of $\mathrm{PCR}$ products were analyzed using electrophoresis in 1.0\% agarose gel (Lonza, Rockland, ME, USA) on a submarine-type apparatus (Mupid-2 plus, Mupid Co., Ltd, Tokyo, Japan). Precisely $10 \mu \mathrm{L}$ of a 250-bp DNA ladder was used as a size marker (Takara Bio Inc.). After electrophoresis, the gel was stained with $50 \mu \mathrm{g} / 100 \mathrm{~mL}$ ethidium bromide solution.

\section{Data analysis}

Data were reported as mean \pm SD or median (range) when not normally distributed. Linear regression analysis was used to examine the relationship between the increases in salivary nitrate/nitrite concentrations after nitrate loading ( $\Delta$ nitrate/nitrite) obtained in the first and second experiments. The differences were analyzed by non-paired $t$-test or Mann-Whitney $U$ test. Statistical significance was set at $P<0.05$. All statistical analyses were carried out by Kaleidagraph 3.6 (HULINKS, Tokyo, Japan).

\section{Results}

Table 1 shows the participants' age, first and second measurements of the baseline nitrate/nitrite concentration, and $\Delta$ nitrate/nitrite concentration after nitrate loading. The numbers of normotensive, grey-zone, and hypertensive participants were 10,2 , and 12 , respectively.

The mean ages of the normotensive and hypertensive participants were significantly different $(65.1 \pm 4.1$ vs. $74.3 \pm 4.0$ years, $P<0.001)$. There were no significant differences in salivary $\Delta$ nitrate/nitrite after nitrate loading between the normotensive and hypertensive participants (Fig. 1). Blood pressure did not change after nitrate loading (data not shown).

Table 2 shows the incidence of Veillonella spp. and $\Delta$ nitrate/nitrite concentrations according to blood pressure. V. atypica, $V$. dispar, and $V$. rogosae were detected in 10 (41.7\%), 24 (100\%), and 14 (38.3\%) participants, respectively. A clear band of $V$. dispar was even seen in 
Table 2 The frequency of $V$. atypica, $V$. dispar, and $V$. rogosae, and increases in salivary nitrate/nitrite concentration after nitrate loading

\begin{tabular}{|c|c|c|c|c|c|c|c|}
\hline Subject & Sex & $\begin{array}{c}\text { Age } \\
\text { (years) }\end{array}$ & $\begin{array}{l}\text { V. atypica } \\
10^{-1} 10^{-2}\end{array}$ & $\begin{array}{l}V . \text { dispar } \\
10^{-1} 10^{-2}\end{array}$ & $\begin{array}{c}\text { V. rogosae } \\
10^{-1} 10^{-2}\end{array}$ & $\Delta$ nitrate, $\mathrm{mM}$ & $\Delta$ nitrite, $\mathrm{mM}$ \\
\hline \multicolumn{8}{|c|}{ Normotensive } \\
\hline \multirow[t]{2}{*}{1} & $\mathrm{f}$ & 70 & -- & +- & -- & 1.80 & 2.48 \\
\hline & & & +- & ++ & + \pm & 0.95 & 1.03 \\
\hline \multirow[t]{2}{*}{2} & $\mathrm{f}$ & 60 & -- & ++ & -- & 2.41 & 0.30 \\
\hline & & & - - & ++ & -- & 1.89 & 0.72 \\
\hline \multirow[t]{2}{*}{3} & $\mathrm{f}$ & 60 & -- & ++ & -- & 1.14 & 1.25 \\
\hline & & & -- & ++ & -- & 1.05 & 0.35 \\
\hline \multirow[t]{2}{*}{4} & $\mathrm{f}$ & 63 & -- & ++ & -- & 0.81 & 0.47 \\
\hline & & & -- & ++ & -- & 0.88 & 0.36 \\
\hline \multirow[t]{2}{*}{5} & $\mathrm{f}$ & 60 & -- & +- & -- & 1.19 & 2.03 \\
\hline & & & +- & ++ & -- & 1.24 & 1.76 \\
\hline \multirow[t]{2}{*}{6} & $\mathrm{~m}$ & 69 & -- & ++ & +- & 2.02 & 0.66 \\
\hline & & & -- & ++ & ++ & 1.67 & 0.71 \\
\hline \multirow[t]{2}{*}{7} & $\mathrm{~m}$ & 69 & +- & ++ & +- & 1.54 & 1.67 \\
\hline & & & +- & ++ & + \pm & 0.79 & 1.47 \\
\hline \multirow[t]{2}{*}{8} & $\mathrm{~m}$ & 69 & -- & ++ & -- & 0.57 & 0.73 \\
\hline & & & -- & ++ & -- & 0.71 & 0.43 \\
\hline \multirow[t]{2}{*}{9} & $\mathrm{f}$ & 65 & -- & ++ & -- & 0.03 & 0.24 \\
\hline & & & +- & ++ & -- & 0.10 & 0.36 \\
\hline \multirow[t]{2}{*}{10} & $\mathrm{f}$ & 66 & -- & ++ & +- & 1.91 & 0.93 \\
\hline & & & -- & ++ & -- & 0.91 & 0.28 \\
\hline \multicolumn{8}{|c|}{ Grey-area (i.e., borderline hypertensive) } \\
\hline \multirow[t]{2}{*}{11} & $\mathrm{f}$ & 76 & \pm- & ++ & \pm- & 1.37 & 0.81 \\
\hline & & & \pm- & ++ & -- & 0.19 & 2.25 \\
\hline \multirow[t]{2}{*}{12} & $\mathrm{f}$ & 68 & -- & ++ & +- & 1.71 & 0.81 \\
\hline & & & +- & ++ & ++ & 0.90 & 0.86 \\
\hline \multicolumn{8}{|c|}{ Hypertensive } \\
\hline \multirow[t]{2}{*}{13} & $\mathrm{~m}$ & 74 & +- & ++ & ++ & 1.94 & 0.97 \\
\hline & & & -- & +- & ++ & 2.06 & 0.96 \\
\hline \multirow[t]{2}{*}{14} & $\mathrm{f}$ & 73 & -- & ++ & -- & 1.67 & 1.80 \\
\hline & & & -- & ++ & -- & 0.86 & 1.86 \\
\hline \multirow[t]{2}{*}{15} & $\mathrm{f}$ & 79 & -- & ++ & +- & 2.17 & 0.84 \\
\hline & & & -- & ++ & + \pm & 2.09 & 0.50 \\
\hline \multirow[t]{2}{*}{16} & $\mathrm{~m}$ & 68 & -- & ++ & -- & 1.22 & 0.04 \\
\hline & & & -- & ++ & -- & 0.74 & 0.11 \\
\hline 17 & $\mathrm{f}$ & 72 & -- & ++ & +- & 1.30 & 0.35 \\
\hline & & & +- & ++ & ++ & 0.80 & 0.44 \\
\hline 18 & $\mathrm{~m}$ & 76 & -- & ++ & +- & 1.70 & 0.43 \\
\hline & & & -- & ++ & -- & 0.98 & 1.07 \\
\hline 19 & $\mathrm{~m}$ & 70 & -- & +- & + \pm & 1.28 & 0.22 \\
\hline & & & -- & + \pm & +- & 0.94 & 0.39 \\
\hline 20 & $\mathrm{~m}$ & 70 & \pm- & ++ & +- & 2.57 & 1.02 \\
\hline & & & +- & ++ & +- & 1.12 & 3.35 \\
\hline 21 & $\mathrm{~m}$ & 77 & +- & ++ & +- & 3.67 & 4.23 \\
\hline & & & +- & ++ & -- & 1.61 & 2.78 \\
\hline 22 & $\mathrm{~m}$ & 78 & -- & ++ & -- & 1.10 & 1.54 \\
\hline & & & -- & + \pm & -- & 1.83 & 0.38 \\
\hline 23 & $\mathrm{~m}$ & 80 & -- & ++ & +- & 1.11 & 1.11 \\
\hline & & & -- & + \pm & +- & 0.51 & 1.34 \\
\hline 24 & $\mathrm{~m}$ & 76 & -- & ++ & -- & 0.71 & 0.44 \\
\hline & & & -- & ++ & -- & 0.45 & 0.38 \\
\hline
\end{tabular}

+ , positive; -, negative; \pm , weak positive. Upper line is first experiment and lower line is second experiment.

participants who produced low amount of salivary nitrite (Fig. 2).

The relationship between the salivary $\Delta$ nitrate/nitrite concentration are depicted in Figure 3. The correlation coefficients were 0.637 for nitrate and 0.583 for nitrite, both of which were statistically significant $(P<0.01)$. Six participants (Nos. 4, 9, 16, 17, 19, and 24) produced relatively low levels of nitrite $(<0.5 \mathrm{mM} \Delta$ nitrite), while seven (Nos. 1, 5, 7, 14, 20, 21, and 23) produced relatively high levels ( $>1.0 \mathrm{mM} \Delta$ nitrite) (Table 2).

\section{Discussion}

There were no significant differences in $\Delta$ nitrate/nitrite after nitrate loading between normotensive and hyperten- 


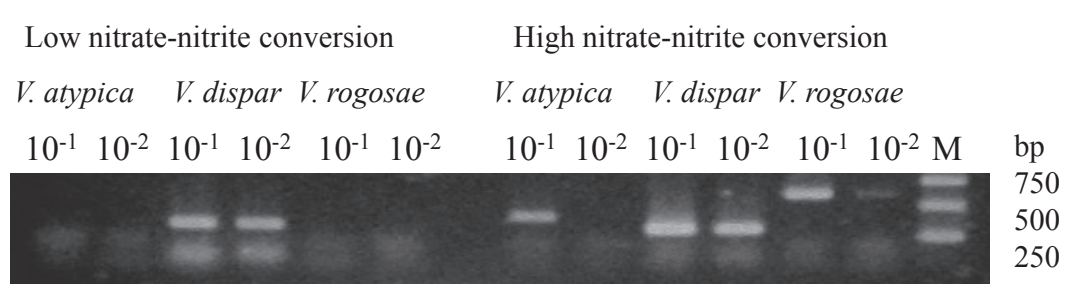

Fig. 2 Analysis of direct PCR performance of $V$. atypica, $V$. dispar, and $V$. rogosae from saliva diluted $10^{-1}$ and $10^{-2}$. Left panel shows a participant with a low capacity for nitrate-nitrite conversion (No. 16); right panel shows a participant with a high capacity for nitrate-nitrite conversion (No. 21). Photographs of electrophoretograms were adjusted brightness using Image J (NIH, https://imagej.nih.gov/ij/).
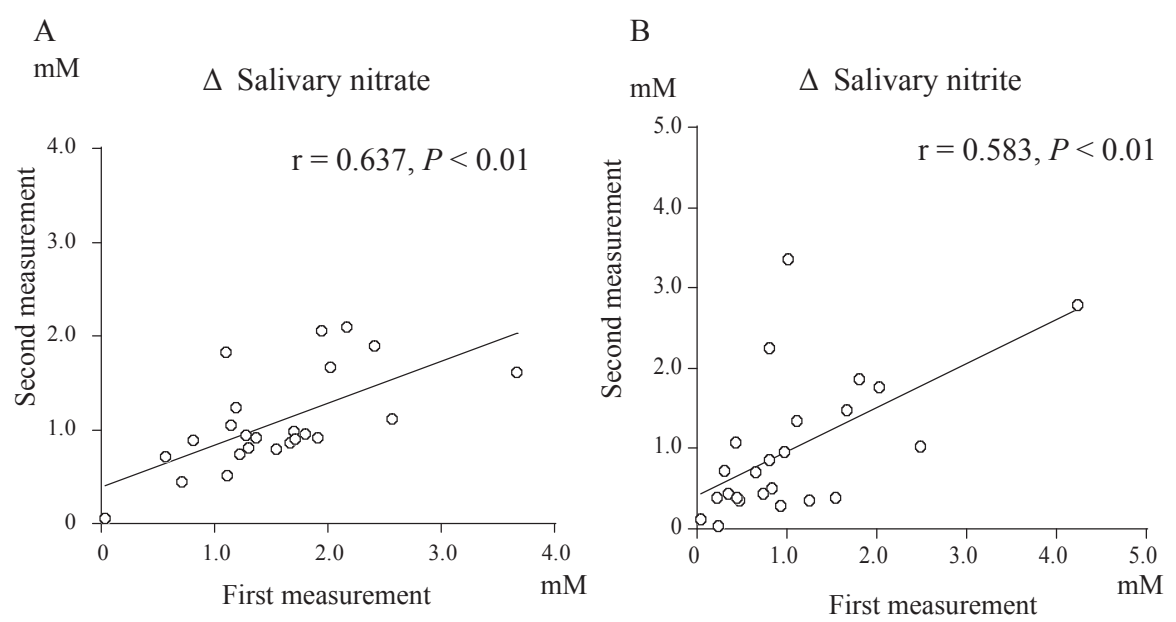

Fig. 3 The relationship between the increases in concentration of salivary (A), nitrate, and (B) nitrite after nitrate loading in the first and second experiments.

sive participants. The significantly higher age ( 9.2 years) of the hypertensive group indicates that nitrate-nitrite conversion capacity does not change with aging. Blood pressure is primarily determined by genetics, aging, diet, and other lifestyle-related factors, and the contribution of the nitrate-nitrite-NO pathway to it is relatively small.

In the present study, large inter-individual variation in saliva nitrate/nitrite concentration was seen, levels after nitrate loading ranging from slightly higher to more than 10 times the baseline level. The nitrate-nitrite-NO pathway is a non-mammalian metabolic process that can be completely abolished by the use of chlorhexidinebased mouthwash, although salivary nitrate concentration is little affected by such mouthwashes (12). The large inter-individual variation in salivary nitrate/nitrite concentration probably occurs because of differences in the capacity for absorption of nitrate in the small intestine, its excretion by the kidneys, and its concentration by the salivary glands, and also the distribution of oral nitrate-reducing microflora.

As shown in Fig. 3, statistically significant relationships were seen between individual participants' salivary $\Delta$ nitrate/nitrite levels in the first and second experiments.
To our knowledge, only one previous study (14) has examined intra-individual variation in salivary nitrate/ nitrite. In that study, $100 \mathrm{~mL}$ of beetroot juice and almost the same level of potassium nitrate $(2.0 \mathrm{mM})$ was administered to participants, and a distinction between subjects with consistently high and low rates of nitrite conversion was suggested. While large day-to-day variations were observed, our results were largely consistent with those previous ones. Our 6 low nitrite-producing participants would certainly have had a lower nitrate-reducing capacity.

In previous studies, cultivable $V$. atypica, $V$. dispar, and $V$. rogosae were isolated from the dorsal surface of the tongue using rров sequencing in $91.0 \%, 81.8 \%$, and $72.7 \%$ of 11 healthy adults, respectively (18), and in $74.0 \%, 55.5 \%$, and $66.7 \%$ of 27 young adults, respectively (21). In a recent study of 89 Thai children, the incidence rates of these Veillonella spp. were $3.4 \%$, $3.4 \%$, and $9.0 \%$, all being lower than those found previously (22). In our present study, $V$. dispar was the most prevalent species $(100 \%)$ with marked DNA bands, while $V$. atypica and $V$. rogosae were detected in $40-60 \%$ of participants. We adopted the direct PCR method because 
it is easy, fast, and low-cost, as it does not require culture. Larger-scale research will be needed to determine how the incidence of Veillonella spp. in the oral cavity relates to aging, race, and oral hygiene.

As Fig. 2 shows, clear bands of $V$. dispar DNA were seen in one subject with low salivary nitrite production (No. 16), while all three Veillonella species were detected in a subject with abundant production (No. 21). Many bacteria in the oral cavity have nitrate/nitrite reductases (15-17), indicating that they may be involved in the nitrate-nitrite-NO pathway. Although the medical community's interest in this pathway has been increasing recently, the organisms that participate in these processes remain poorly understood. To improve our understanding of nitrate metabolism in the intestinal tract and its effects on the human body, more information on oral nitratereducing bacteria is required.

In conclusion, $V$. dispar was detected even in participants with a reduced capacity for nitrate-nitrite conversion. The conversion of salivary nitrate-nitrite is not affected by aging or blood pressure. This inter- and intra-individual variation may affect how individuals receive the benefits of dietary nitrate, such as through lower blood pressure and efficient oxygen consumption.

\section{Acknowledgments}

This work was supported by a grant from the Organization for Research Promotion, Iwate University.

\section{Conflict of interest}

None declared.

\section{References}

1. McKnight GM, Duncan CW, Leifert C, Golden MH (1999) Dietary nitrate in man: friend or foe? Br J Nutr 81, 349-358.

2. Larsen FJ, Ekblom B, Sahlin K, Lundberg JO, Weitzberg E (2006) Effects of dietary nitrate on blood pressure in healthy volunteers. N Engl J Med 355, 2792-2793.

3. Sobko T, Marcus C, Govoni M, Kamiya S (2010) Dietary nitrate in Japanese traditional foods lowers diastolic blood pressure in healthy volunteers. Nitric Oxide 22, 136-140.

4. Hughes WE, Ueda K, Treichler DP, Casey DP (2016) Effects of acute dietary nitrate supplementation on aortic blood pressure and aortic augmentation index in young and older adults. Nitric Oxide 59, 21-27.

5. Larsen FJ, Schiffer TA, Ekblom B, Mattsson MP, Checa A, Wheelock CE et al. (2014) Dietary nitrate reduces resting metabolic rate: a randomized, crossover study in humans. Am J Clin Nutr 99, 843-850.

6. Doel JJ, Hector MP, Amirtham CV, Al-Anzan LA, Benjamin N, Allaker RP (2004) Protective effect of salivary nitrate and microbial nitrate reductase activity against caries. Eur J Oral
Sci 112, 424-428.

7. Mitsui T, Fujihara M, Harasawa R (2013) Salivary nitrate and nitrite may have antimicrobial effects on Desulfovibrio species. Biosci Biotechnol Biochem 77, 2489-2491.

8. Yamamoto Y, Washio J, Shimizu K, Igarashi K, Takahashi N (2017) Inhibitory effects of nitrite on acid production in dental plaque in children. Oral Health Prev Dent 15, 153-156.

9. Dykhuizen RS, Fraser A, McKenzie H, Golden M, Leifert C, Benjamin N (1998) Helicobacter pylori is killed by nitrite under acidic conditions. Gut 42, 334-337.

10. Weitzberg E, Lundberg JO (2013) Novel aspects of dietary nitrate and human health. Annu Rev Nutr 33, 129-159.

11. Eisenbrand G, Spiegelhalder B, Preussmann R (1980) Nitrate and nitrite in saliva. Oncology 37, 227-231.

12. Govoni M, Jansson EA, Weitzberg E, Lundberg JO (2008) The increase in plasma nitrite after a dietary nitrate load is markedly attenuated by an antibacterial mouthwash. Nitric Oxide 19, 333-337.

13. Hart RJ, Walters CL (1983) The formation of nitrite and $\mathrm{N}$-nitroso compounds in salivas in vitro and in vivo. Food Chem Toxicol 21, 749-753.

14. Bos PM, Van den Brandt PA, Wedel M, Ockhuizen T (1988) The reproducibility of the conversion of nitrate to nitrite in human saliva after a nitrate load. Food Chem Toxicol 26, 93-97.

15. Palmerini CA, Palombari R, Perito S, Arienti G (2003) NO synthesis in human saliva. Free Radic Res 37, 29-31.

16. Doel JJ, Benjamin N, Hector MP, Rogers M, Allaker RP (2005) Evaluation of bacterial nitrate reduction in the human oral cavity. Eur J Oral Sci 113, 14-19.

17. Hyde ER, Andrade F, Vaksman Z, Parthasarathy K, Jiang H, Parthasarathy DK et al. (2014) Metagenomic analysis of nitrate-reducing bacteria in the oral cavity: implications for nitric oxide homeostasis. PLoS One 9, e88645.

18. Beighton D, Clark D, Hanakuka B, Gilbert S, Do T (2008) The predominant cultivable Veillonella spp. of the tongue of healthy adults identified using rpoB sequencing. Oral Microbiol Immunol 23, 344-347.

19. Igarashi E, Kamaguchi A, Fujita M, Miyakawa H, Nakazawa F (2009) Identification of oral species of the genus Veillonella by polymerase chain reaction. Oral Microbiol Immunol 24, 310-313.

20. Nilsson M, Grånemo J, Buś MM, Havsjö M, Allen M (2016) Comparison of DNA polymerases for improved forensic analysis of challenging samples. Forensic Sci Int Genet 24, 55-59.

21. Mashima I, Kamaguchi A, Nakazawa F (2011) The distribution and frequency of oral Veillonella spp. in the tongue biofilm of healthy young adults. Curr Microbiol 63, 403-407.

22. Mashima I, Theodorea CF, Thaweboon B, Thaweboon S, Nakazawa F (2016) Identification of Veillonella species in the tongue biofilm by using a novel one-step polymerase chain reaction method. PLoS One 11, e0157516. 